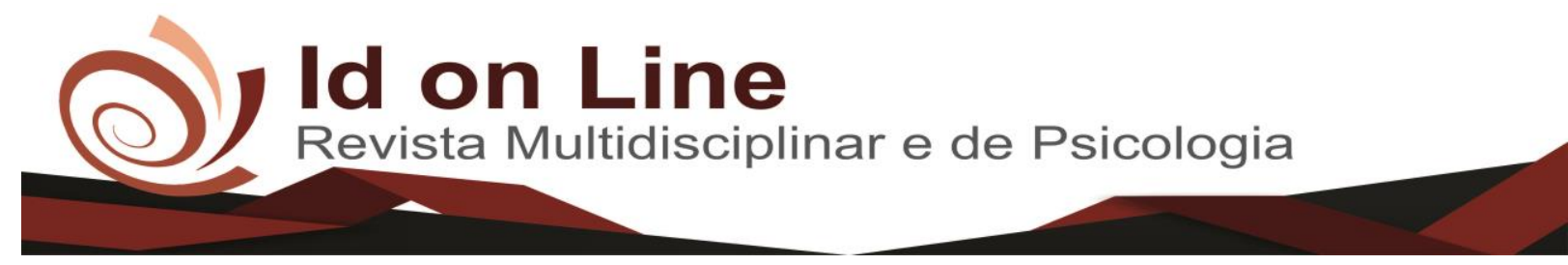

Artigo

\title{
Redes Sociais e Mercado Fotográfico do Vale do São Francisco
}

\author{
Silvio Stanislaw Alves de Oliveira ${ }^{1}$; Hesler Piedade Caffé Filho ${ }^{2}$.
}

\begin{abstract}
Resumo: Com o crescimento do mercado de fotografia no Vale do São Francisco, surgiu a necessidade de desenvolver essa pesquisa procurando mostrar a forma com que os consumidores de serviços fotográficos da região se comportam. Com embasamento teórico em marketing e fotografia, tornou-se possível transformar esse trabalho em um manual de relacionamento com os clientes, os conhecendo através dos perfis analisados. Assim foi possível descrever como os clientes se envolvem virtualmente com as publicações e anúncios de fotógrafos nas redes, de acordo com sua posição e classe social. A criação de persona auxilia na produção do planejamento de marketing nas redes sociais dos fotógrafos, conhecendo-as detalhadamente a forma com que consome dentro e fora das redes, ajuda-nos a entender e buscar alternativas objetivas de atingir o público alvo de maneira eficaz. O método da pesquisa trabalha de forma objetiva trazendo uma pesquisa de caráter quantitativo, exploratória e descritiva, utilizando-se de plataformas virtuais, facilitando a interpretação dos dados da amostra proposta. Através da criação de um planejamento e análise de fluxo de acessos nas redes, este trabalho busca otimizar e potencializar o envolvimento das personas com os fotógrafos nas redes sociais.
\end{abstract}

Palavras-Chave: Redes Sociais; Persona; Marketing; Fotografia.

\section{Social Media and the Photographic Market of São Francisco Valley}

\begin{abstract}
With the growth of the photography market in the São Francisco Valley, there is a need to develop this research in electronic format. With theoretical basis in marketing and photography, it became possible to transform this work into a manual of relationship with the clients, knowing it through the analyzed profiles. Thus, it was possible to describe how clients become virtually involved as publications and ads of photographers in the networks, according to their position and social class. The creation of personality in the production of marketing planning in photographers' social networks, knowing in detail how it consumes inside and outside the networks, helps us to understand and look for objective alternatives to control the target public in an efficient way. The method of the research of work of objective form bringing a research of quantitative character, exploratory and descriptive, using of virtual platforms, facilitating an interpretation of the data of the proposed sample. Through the creation of a network access planning and analysis, this work seeks to optimize and enhance the involvement of people with photographers in social networks.
\end{abstract}

Keywords: Social Networks; Person; Marketing; Photography.

${ }^{1}$ Formado em Comunicação Social com ênfase em Publicidade e Propaganda pela Faculdade São Francisco de Juazeiro, Discente do MBA de Gestão Empresarial e Marketing na Faculdade São Francisco de Juazeiro-BA. Contato: silvio.stanislaw@gmail.com;

${ }^{2}$ Administrador pela Estácio de Sá; MBA em Gestão Estratégica de Negócios pela Escola de Engenharia Eletromecânica da Bahia; Especialista em Marketing Institucional pela Faculdade São Francisco de Juazeiro (2009); Mestre em Gestão de Políticas Públicas pela Universidade Federal do Recôncavo da Bahia. Administrador da Universidade Federal do Vale do São Francisco, Professor da Faculdade São Francisco de Juazeiro; Professor da Universidade Federal do Vale do São Francisco. Contato: hesler.caffe@ univasf.edu.br. 


\section{Introdução}

Os fotógrafos, desenvolveram uma nova forma de olhar o mundo e os acontecimentos da humanidade, com técnicas de luz e sombra. Na modernidade essa cultura de fotografar tornou-se instrumento de trabalho, criando a necessidade de um gerenciamento de clientes e serviços, e a preocupação em falar a mesma linguagem de seus admiradores.

O estudo delimitou a pesquisa para o Vale do São Francisco, já que desde o princípio das atividades acadêmicas de graduação, o pesquisador sentiu a necessidade de contribuir de uma forma mais científica para a melhoria da prestação de serviços fotógrafos na região. A necessidade de aprofundar os conhecimentos relacionados aos comportamentos dos clientes dos fotógrafos do Vale do São Francisco, o interesse em criar estratégias mais eficazes de atingir o público-alvo, conduziram as análises que compõe este trabalho. Continuar a desenvolver um trabalho que se torne referência no assunto de estudo mercadológico na região afim de contribuir outras pesquisas de mesmo caráter no Vale do São Francisco.

Com um papel indispensável em qualquer eventualidade, o fotógrafo traz consigo a responsabilidade de satisfazer o cliente da melhor maneira possível, procurando a forma mais eficaz de seduzir seu cliente, interagir como ele e proporcionar a oportunidade de rever um grande momento de sua vida em forma de fotografia. Para saber como tudo isso acontece e através de que ferramentas online é possível, foi desenvolvido este material para levar ao conhecimento do mercado de vendas de produtos e serviços fotográficos através da internet e redes sociais.

De acordo com as características mais comuns de clientes, esta pesquisa desenvolve caráter analítico que incentiva a busca pela melhoria da qualidade de direcionamento de comunicação dos profissionais de fotografia, no seu trabalho com mídias virtuais, trazendo através de estudos, um acervo de informações visando instruir um melhor posicionamento da empresa/marca no mercado através das redes sociais.

O marketing digital não consiste no resultado de erros e acertos, traz consigo o mérito de diversos estudos comportamentais dentro das redes que refletem no consumo no mercado físico, na conversão de cliques em valores monetários. Desde a definição de cybermarketing por Cobra (2002), a forma de conquistar e envolver seguidores, de uma forma que esses não percam o interesse rapidamente pelo seu conteúdo, mudou totalmente, sendo necessário, na 
maioria das vezes, mostrar ao público a face humana da empresa, que tem sentimentos e que se preocupa com que os seus clientes querem ver.

Com o surgimento das redes sociais a necessidade de desenvolver personas ${ }^{3}$ tornou-se importante para a estratégia de marketing, essas personas são o público-alvo das empresas. Desta forma, fica mais fácil de planejar a produção de conteúdo para prospectar novos clientes, conhecendo os vários públicos que deseja atingir, é necessário pensar nas características de compra, comportamento nas redes, formas de pagamento, entre outros, assim, no desenvolver deste trabalho, a criação de personas para análise de venda e posicionamento foi necessária para melhor aproveitamento do tema.

Por fim, o objetivo desse artigo é entender como o mercado fotográfico se comporta nas redes sociais e como sofre influência na compra do produto ou serviço.

a) Analisar o perfil dos possíveis consumidores do mercado de fotografia de acordo com sua cultura, classe social e região

b) Ilustrar a forma com que as ferramentas virtuais, usadas pelos fotógrafos, conseguem interagir com os consumidores descritos no item anterior.

\section{Metodologia}

Ao longo desta pesquisa, foram desenvolvidas estratégias de coleta de dados que ajudem a chegar a resultados sobre os assuntos do mercado de fotografia, marketing, perfil de consumidores e fotógrafos. Com a ajuda de embasamento teórico já estudado, foi desenvolvido um modelo de análise contendo elementos chave para execução desse trabalho acadêmico que visa criar um acervo de informações, que será necessário para uma análise dos problemas apresentados anteriormente, que por sua vez, foi norteado pelo objetivo desta pesquisa.

O ambiente de pesquisa é caracterizado como intencional. A amostra para entrevista foram os fotógrafos profissionais localizados nas cidades de Juazeiro e Petrolina, aqui denominado "Região do Vale do São Francisco"”.

\footnotetext{
${ }^{3}$ Personas são personagens fictícios criados para representar os diferentes tipos de usuário dentro de um alvo demográfico, atitude e/ou comportamento definido que poderia utilizar um site, uma marca ou produto de um modo similar. Personas são uma ferramenta ou método de segmentação de mercado. O termo persona é usado amplamente em aplicações online e tecnológicas, bem como em publicidade, onde outros termos como retratos de pena também podem ser usados. Fonte: Wikipedia.

${ }^{4}$ Integram-se esta zona cerca de 900 municípios, com população de aproximadamente 17 milhões de habitantes. Está situada no submédio do Rio São Francisco. Fonte: Ministério da Agricultura, Pecuária e Abastecimento, informações disponíveis em http://www.cnpma.embrapa.br/projetos/prod_int/regiaosf.html
} 
A pesquisa aconteceu no período de 01 a 21 de novembro de 2016, com o universo de 25 fotógrafos profissionais. Para ampliar e aperfeiçoar o recebimento das respostas, foi utilizado o formato Google Drive ser uma ferramenta de coleta e registro de formulário eletrônico. Os questionários podem ser respondidos via computador pessoal, tablet, smartphone ou notebook, desde que os aparelhos estejam conectados à internet. Com essa ferramenta, o resultado pôde ser acompanhado em tempo real. A chamada para responder os questionários e as entrevistas foi através de E-mail e redes sociais (Facebook e WhatsApp). O texto chamou atenção para a importância da pesquisa tanto no quesito mercadológico quanto profissional.

Trata-se de uma pesquisa quantitativa pois a natureza visa traduzir em números determinadas informações coletadas ao longo do processo. O estudo quantitativo consiste em investigações de pesquisa empírica cuja principal finalidade é o delineamento ou análise das características de fatos ou fenômenos, a avaliação de programas, ou o isolamento de variáveis principais ou chave (LAKATOS, 1991).

Em relação à escolha do instrumento de coleta, optou-se pelo modelo de questionário pela objetividade das perguntas e pela qualidade de análise que a plataforma proporciona no final da pesquisa, podendo formatar gráficos e representação numérica dos perfis dos profissionais e suas características. O questionário virtual, utilizando a plataforma de formulários virtuais ${ }^{5}$ da "Google", é iniciado o processo exploratório de conhecimento de cada profissional e seu modo de trabalho que serão identificados e categorizados de acordo com seu perfil de público em que se encaixa dentro do mercado fotográfico.

Trata-se também de uma pesquisa descritiva, pois observa, registra, analisa e correlaciona fatos ou fenômenos sem manipulá-los. Procura-se descobrir, com maior precisão possível, a frequência com que um fenômeno ocorre, sua relação e conexão com outros, sua natureza e suas características. Busca-se conhecer as diversas situações e relações que ocorrem na vida social, política, econômica e demais aspectos do comportamento humano, tanto do indivíduo tomado isoladamente como de grupos e comunidades mais complexas. (CERVO et al., 2007)

Para Cervo, Bervian e da Silva (2007, p.61), a pesquisa descritiva ocorre quando se registra, analisa e correlaciona fatos ou fenômenos, sem manipulá-los. Ainda de acordo com Cervo, Bervian e da Silva (2007, p.62), esta modalidade de pesquisa pode assumir diversas

\footnotetext{
${ }^{5}$ Ferramenta virtual da empresa Google, onde é possível fazer uma votação, uma pesquisa, um teste ou coletar informações em um formulário através das Planilhas da Plataforma Google Drive, pelo endereço eletrônico "docs.google.com/forms" 
formas, e umas delas se encaixam nesta pesquisa como os estudos descritivos e a pesquisa de motivação.

Estuda-se e descreve características de como os profissionais de fotografia se comportam dentro do mercado em relação a seu público, sendo demonstrado através da ferramenta de questionário fechado e estruturado.

Este tipo de pesquisa é normalmente o passo inicial no processo de pesquisa pela experiência e pelo auxílio que traz a formulação de hipóteses significativas para posteriores pesquisas. A pesquisa exploratória realiza descrições precisas da situação e quer descobrir as relações existentes entre seus elementos componentes. (Cervo et al., 2007).

É ainda uma pesquisa exploratória, pois visa à descoberta, o achado, a elucidação de fenômenos ou a explicação daqueles que não eram aceitos apesar de evidentes. A exploração representa, atualmente, um importante diferencial competitivo em termos de concorrência (Gonçalves, 2014).

É importante estabelecer contato com o entrevistado através de uma apresentação de objetivo e metas da pesquisa e do questionário, podendo apresentar logo após as questões relacionadas ao tópico da pesquisa; A validação: deve-se garantir que o questionário esteja alinhado aos objetivos propostos; Determinação do método de aplicação: o questionário pode ser auto administrado, aplicado por correspondência ou aplicado eletronicamente (HAIR et al., 2005, p. 160 apud MOYSÉS e MOORI, 2007).

A elaboração de um questionário exige uma dedicação e atenção adequada para transformar sua pesquisa em uma ferramenta importante a fim de comprovar a veracidade de resultados que se desconfiava e precisava ser comprovado. O questionário é um instrumento desenvolvido cientificamente, composto de um conjunto de perguntas ordenadas de acordo com um critério predeterminado, que deve ser respondido sem a presença do entrevistador (MARCONI; LAKATOS, 1999, P.100) e que tem por objetivo coletar dados de um grupo de respondentes.

A temática desta pesquisa ainda é atual, mas trata-se de um aprofundamento de pesquisa anterior produzida pelo próprio autor. Desta forma, alguns estudos de pesquisa semelhantes poderão auxiliar na forma de decidir a melhor forma de coleta de dados. Os levantamentos bibliográficos de maior representação neste trabalho, são teóricos dos campos da psicologia do consumidor, marketing, publicidade e fotografia. 
A coleta de dados teve a contribuição de diversos fotógrafos da região do Vale do São Francisco, de sexos e idades diferentes, tempo de mercado e profissionais de diversas áreas da fotografia e que responderam o questionário de forma virtual. Esse método pode vir a ser mais eficaz utilizando-se de uma entrevista semiestruturada para obter resultados mais conclusivos sobre o modo de atuação no mercado, reduzindo as chances de que os entrevistados deixem algum fator importante passar desapercebido pelo entrevistador, garantindo uma exatidão maior nos resultados obtidos. Nesse processo os fotógrafos fornecem informações do perfil de seu público e a forma com que dirigem suas funções, sejam eles com pouco ou muito tempo de atuação no mercado.

\section{Marketing e Seus Conceitos}

O marketing é a atividade humana que tem por objetivo satisfazer as necessidades e desejos dos consumidores e de seus stakeholders ${ }^{6}$ por meio de um produto, serviço ou ideias (Cobra, 1992; Kotler, 1996; Las Casas, 2001; Oliveira, 2007).

O conceito de marketing foi definido no pós-guerra na década de 1950, quando o comércio passou a considerar não somente a qualidade dos produtos e custos competitivos, mas principalmente entender os desejos de seus clientes (KELLER, KOTLER, 2006).

Marcos Cobra (2001) explica que a necessidade de vender, saber para quem vender, planejar as condições e preços, foram propulsoras para o desenvolvimento do marketing ainda na época da revolução industrial.

Raimar Richers (1926) traz uma primeira definição do composto de marketing com os 4As (Análise, Adaptação, Ativação e Avaliação). Jerome McCarthy (1960), vendo necessidade de concentrar os esforços na venda de um produto, a abordagem centrou-se na determinação do preço capaz de gerar vendas, apoiada numa promoção de vendas, propaganda e merchandising atraente e sedutora, por meio ainda de uma distribuição ampla e/ou estratégica.

Após isso, Robert Lauterborn (1990), da Universidade da Carolina do Norte, afirmou que a teoria dos 4Ps deveria ser abandonada e adotar os 4 Cs do cliente, da Conveniência, do Custo e da Comunicação, passando o cliente a ser o foco primordial do composto de marketing.

\footnotetext{
${ }^{6}$ Stakeholders são as "partes interessadas” nas ações e opiniões da organização. O termo vem do inglês e é utilizado para designar os indivíduos ou grupos afetados pela empresa. Fonte:http://marketingfuturo.com/o-que-e-stakeholder-conceito-e-definicao-de-stakeholders/.
} 
A partir de 2004, com a nova definição de marketing pela AMA (American Marketing Association) da palavra marketing "como sendo uma função organizacional e uma série de processos para criação, comunicação e entrega de valor para clientes, e gerenciamento de relacionamento com os clientes de forma a beneficiar a organização e seus públicos de interesse, ou stakeholders".

O marketing evoluiu seus objetivos com o passar dos anos, observando a mudança de comportamento dos clientes e a forma com que eles consumiam determinados serviços e produtos. De acordo com a classificação das fases do marketing de Cobra (2002), estamos vivendo no período do cybermarketing desde 1996, onde a internet e o comércio eletrônico estão mudando os hábitos de comunicação e consumo, chamado também de marketing experiencial.

\section{Marketing Digital}

Conforme Drucker (1999), um dos grandes desafios gerenciais a ser enfrentado pelas organizações atuais é a necessidade de a empresa estar preparada para agir em um ambiente de mudanças constantes. A internet é um ambiente rapidamente mutável, que proporcionam maneiras variadas das pessoas consumirem produtos, causando impacto no modelo tradicional do marketing, deixando de ser vista apenas como um canal de pesquisas e entretenimento.

Os consumidores querem ter flexibilidade de escolha e escutar o que dizem sobre a marca, opiniões isentas e objetivas de pessoas comuns como ele. As pessoas querem exercer o poder de escolha que têm para adquirir a solução que acreditam ser a melhor, e não a que a empresa lhes diga. Ferramentas para pesquisa eles tem - a internet e as redes sociais se apresentam fortemente, com uma enorme quantidade de elementos para que eles exerçam tal poder - a era do 'vender' dá lugar à do ‘ajudar a comprar'” (VAZ, 2010, p. 69).

\section{Planejamento Estratégico nas Redes Sociais}

Antes de qualquer decisão, o profissional de fotografia deve ter noção que o seu perfil em redes sociais é apenas uma mídia complementar e que não veio para substituir seu site, mas para complementar e interagir melhor com seu público. $44 \%$ dos fotógrafos não mantém site 
ou blog ativos e não entendem que as redes sociais funcionam apenas como mídia complementar.

O site é a casa virtual do fotógrafo, é onde ele guarda o seu portfolio sem se preocupar com a instabilidade das redes sociais, o risco de perda de qualidade e falência da empresa responsável. Assim o blog assume como um diário de bordo das atividades profissionais como cursos, viagens, dicas contemporâneas aos clientes, é o espaço virtual onde os clientes sentemse íntimos do fotógrafo e criam uma relação de admiração de suas inspirações.

\section{Gráfico 01 - Ferramentas de portfólio online}

\section{UTILIZAÇÃO DE SITE/BLOG}

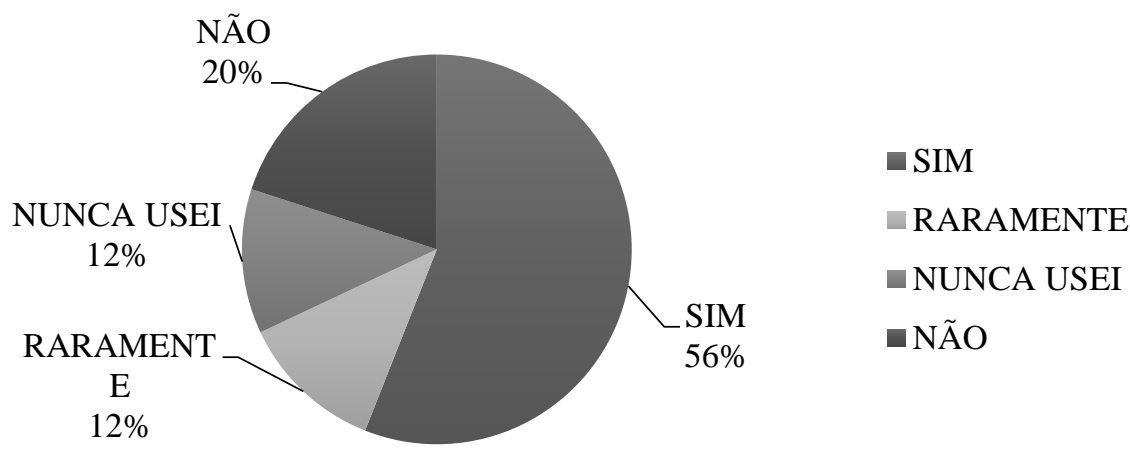

Fonte: Oliveira (2016).

A definição de uma estratégia que o profissional irá adotar na sua comunicação, é o primeiro passo seguido, reunindo recursos como personas e estrutura do planejamento. É necessário que o primeiro passo seja estabelecer objetivos esperados, claros e possíveis, que sejam de fácil envolvimento do público. Através do monitoramento da campanha, é possível entender se a estratégia está alinhada com o objetivo e alcançando resultados positivos.

Para garantir o máximo de aproveitamento da campanha, os profissionais devem adotar o método SMART para aumentar a possibilidade de sucesso da campanha. Funciona como um checklist, verificando o andamento de cada etapa do planejamento. A palavra "SMART" é formada pelas iniciais, em inglês, de 5 etapas:

- $\mathbf{S}$ - Específica (specific), nesta etapa serão definidas as metas de sua presença nas redes, o que/quem serão obrigatoriamente atingidos e mensurados através de representação numérica e dados. 
- $\quad \mathbf{M}$ - Mensurável (measurable), toda meta deverá ter um indicador, que sinalize o quando as metas estão sendo cumpridas.

- A - Atingível (attainable), nessa etapa são avaliadas as metas que são ousadas, atingíveis ou alcançáveis, mas levando em conta a real possibilidade de atingilas.

- $\mathbf{R}$ - Relevante (realistic), para o objetivo geral da estratégia ter um bom resultado, cada meta precisa ser importante para o objetivo coletivo da empresa. Nesta etapa, as metas devem ser classificadas como prioridades para ajudar no direcionamento estratégico do objetivo principal da empresa.

- $\mathbf{T}$ - Temporizável (time bound), toda meta precisa de um prazo para ser atingida e esforço necessário para não as deixar incompletas.

\section{Análise de Mercado}

É necessário saber como o setor fotográfico se movimenta nas redes. A pesquisa e análise de mercado faz-se importante para metrificar o público que será alvo das campanhas e a forma com que a concorrência interage. Algumas estratégias como marketing de conteúdo, atendimento online pelas redes sociais e comunicadores instantâneos (whatsapp, telegram) são capazes de criar uma identidade sólida na internet.

Ao identificar o canal mais eficaz para comunicação com seu público, já que nem todo mundo faz o uso das redes sociais, o profissional precisa padronizar uma linguagem com base nos costumes e características de seus seguidores. De acordo com as características o público direciona-se para determinada rede, procurando o lugar que mais lhe agrada e o mantenha inserido em um grupo.

A avaliação em números facilita na decisão de direcionar os investimentos em mídia. Segundo um levantamento do Instituto Data Popular em parceria com a WebSIA, em 2009, a nova distribuição socioeconômica do mundo virtual reflete melhor o que acontece na sociedade brasileira "real". Segundo dados oficiais, a classe C abrange 53\% da população, a classe DE tem $27 \%$ e a classe AB, 20\%. A proporção também corresponde à presença das classes sociais na internet como um todo, segundo a Pesquisa Nacional por Amostras de Domicílio: entre os 75 milhões de internautas brasileiros, $48 \%$ são da classe média, $44 \%$ da classe alta e $8 \%$ da classe baixa.

As classes em ascensão financeira têm compreendido a importância da fotografia no cotidiano. Os grupos de referência têm sido aliados nesse quesito, onde aprendem a dar valor a 
contratação de profissionais qualificados para registrar um evento. Mesmo comprando o pacote mais simples, é possível compreender que os clientes preferem ter os registros em formatos digitais do que perder a oportunidade de registrar.

Gráfico 02 - Representação socioeconômica dos clientes

\section{CLASSE ECONÔMICA PREDOMINANTE ENTRE OS CLIENTES DE FOTOGRAFOS DO VALE DO S.F.}

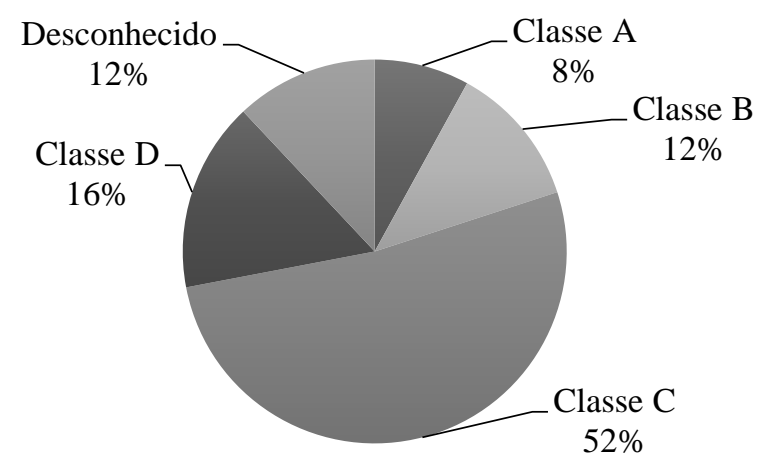

- Classe A

- Classe B

- Classe C

- Classe D

- Desconhecido

Fonte: Oliveira (2016).

Essas pessoas, possíveis consumidores de fotografia, que compõe a classe $\mathrm{C}$, ocupando $52 \%$ dos consumidores dos fotógrafos da amostra, estão presentes nas redes sociais, principalmente o Facebook. A rede tornou-se uma vitrine de fotógrafos que procuram baixo investimento e assim consegue atingir a classe mais baixa.

Ainda segundo o estudo do Instituto Data Popular, agora a classe C tem 56\% dos usuários do Facebook (contra 24\% da elite) e 55\% do Twitter (também contra 24\% da elite). Bem semelhante ao Orkut, que tinha $57 \%$ de classe $\mathrm{C}$ e $23 \%$ de classe $\mathrm{AB}$, proporção que o site já registrava em 2009, quando contava com $50 \%$ de classe C e $34 \%$ de classe AB.

\section{Marketing de Conteúdo}

A internet tem sido uma ferramenta essencial para ter contato com o nosso público e clientes. Através das redes sociais (Instagram e Facebook), os fotógrafos encontraram a oportunidade de trabalhar o envolvimento das pessoas com suas postagens e histórias, 
utilizando estratégias como o marketing inbound, marketing de conteúdo, os profissionais conseguem falar a mesma linguagem das pessoas que se encaixam em seu público-alvo.

A rede social que conquistou o mercado fotográfico e tem gerado resultados vertiginosos, Instagram, desenvolvido em 2010, atualmente, o Instagram conta com mais de 100 milhões de usuários em todo o planeta. Hoje uma ferramenta muito utilizada por fotógrafos pela possibilidade de direcionar seu público através do sistema de Tags dentro de suas postagens, aumentando a visualização de suas publicações, isso aumenta a visibilidade de seu trabalho e a forma dos clientes lembrarem de sua presença dentro da rede social. Silva (2012) apresenta o aplicativo como um espaço em que os indivíduos se materializam. Para Silva, a ferramenta citada está na moda e consegue extrair do usuário suas experiências e suas intimidades.

O Instagram foi considerado como uma rede social emergente (Recuero apud PIRES, 2013, p. 28), tendo seu sucesso instantâneo chamando atenção do Facebook. Outra importante ferramenta utilizada por $100 \%$ dos fotógrafos que participaram da pesquisa e que hoje possui a maior parcela de usuários da internet, graças também pela interação de ambas as redes, possibilitada pela compra do Instagram pelo Facebook.

O "insta”, demonstra-se uma ferramenta voltada para públicos específicos, de classes mais elevadas, que procuram mais privacidade e fogem de redes sociais mais hostis como o Facebook. O aplicativo agora traz a novidade de vídeos, onde os seguidores podem interagir melhor com seus contatos, ferramenta esta que ajuda o fotógrafo a estar mais perto do cotidiano de seus clientes, é uma poderosa opção para investimentos com publicações patrocinadas se utilizadas com orientação correta de um especialista.

Gráfico 03 - Envolvimento dos fotógrafos no Instagram

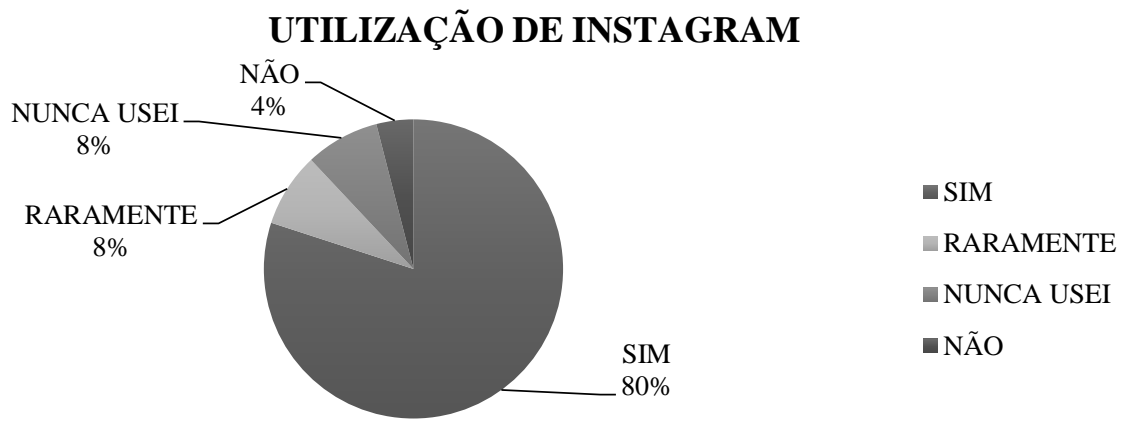

Fonte: Oliveira (2016). 
Para bons resultados, é necessário um planejamento estratégico dentro das redes sociais. Definindo corretamente Target, posicionamento do fotógrafo, um monitoramento de fluxo de visualização e como o público interage com cada conteúdo.

A cada dia, as redes sociais desenvolvem um algoritmo capaz de limitar ou alterar a forma com que os posts atinjam outros usuários, assim é importante gerar conteúdo que atraia a atenção dos seguidores.

Um exemplo disso é a utilização de vídeos, segundo Zimmerman (2017), consultora e especialista em Instagram, é um conteúdo que tem o melhor ROI (Return on Investment, ou Retorno sobre Investimento, em português). Assim, as postagens com mais curtidas aparecem mais que as outras, pois são colocadas em prioridade de visualização de quem busca novo conteúdo.

\section{Monitoramento}

O comportamento e a forma de se posicionar nas redes sociais, principalmente para fotógrafos, depende do objetivo do profissional e o do tipo de público que ele desejar atingir com suas postagens.

As publicações de fotografia social são vistas por alguns grupos direcionados, clientes, clientes em potencial, fornecedores do ramo de eventos da região (buffet, doceiras, decoradoras, iluminadores, cerimoniais, cinegrafistas), amantes de fotografia, usuários que buscam inspiração para suas festas, familiares e amigos dos fotografados e concorrentes. Esses seguidores buscam estar informados do que está acontecendo durante o trabalho dos fotógrafos, quem estará nas postagens e qual a novidade de promoção que pode por ventura acontecer.

Os seguidores dos fotógrafos acompanham o cotidiano de ensaios, eventos, editoriais, diversão, gostam de sentir-se amigos próximos, principalmente quem já tem um relacionamento de cliente antigo. A criação de uma rotina de postagens seguido da linguagem adotada anteriormente e dos horários planejados, permite mensurar os resultados de como anda as metas estabelecidas no planejamento de marketing. Assim, é possível entender do público de cada fotógrafo. 
Poderosa rede social no meio fotográfico, o Instagram já ultrapassa 500 milhões de usuários, só no Brasil, são cerca de 35 milhões de pessoas conectadas à rede. Além da qualidade das imagens, esta rede permite direcionar suas postagens através do uso de hastags, sendo um diferencial para os fotógrafos. O que não elimina a possibilidade de continuar com o site oficial, sendo este o mais completo meio de divulgação da marca, tendo o endereço vinculado à conta.

\section{P's}

O trabalho de um fotógrafo é valorizado por suas habilidades artísticas, contudo, assim como outros negócios, o conjunto de preço, praça, promoção e seus serviços podem ser decisivos para fechar novos negócios. Os fatores, conhecidos como os 4Ps do marketing, quando nos referimos ao produto por ele oferecido, precisam ser desenvolvidos em harmonia para se alcançar os objetivos pretendidos. Vejamos:

- Produto, o profissional de fotografia deve ter em conta todos os componentes do desempenho do serviço. A empresa deve vender o sonho de realização de ter aquele momento eternizado com delicadeza e emoção;

- Lugar e tempo, é necessário definir quando (tempo de entrega do álbum), onde (local) e como (meios) o serviço será entregue/prestado aos clientes. Dependendo do grau de relacionamento do fotógrafo com seus clientes todos esses pontos influenciarão diretamente na fidelização do consumidor;

- Promoção e educação, parte da comunicação é, por natureza, educacional, particularmente para clientes novos. É preciso desenvolver um processo educacional do público estimulando nas pessoas a necessidade de buscar registrar cada momento seja em família ou corporativo, cuidando para que a fotografia torne a ser um investimento imprescindível do cotidiano. Segundo Solomon (2002), a aprendizagem é uma mudança relativamente permanente no comportamento causada pela experiência;

- Preço. Neste ponto o fotógrafo desenvolve uma análise do valor de seu trabalho, sendo necessário ter em conta outros custos dos quais os clientes possam incorrer para obterem benefícios do produto. Os serviços são essencialmente intangíveis e por isso devem estar associados a algo tangível, ou seja, um produto. A definição de todas estas variáveis é de suma importância para que os serviços sejam bem executados. Para o cliente o preço deve oferecer uma relação custo x benefício satisfatório e melhor que os concorrentes (LAS CASAS, 2005). Para Kotler e Armstrong (1993), as decisões de preços de uma empresa são afetadas por muitos fatores internos e externos. "Os fatores internos incluem os objetivos de marketing da empresa, sua estratégia de mix de marketing, custos e organização. Os fatores externos incluem a natureza do mercado, a demanda, a concorrência e outros fatores ambientais". 


\section{A Persona}

Conhecer seu público é um dos primeiros passos para uma comunicação eficaz no mercado fotográfico. Para isso ser possível, é necessário criar uma "persona”, uma pessoa fictícia com características que levam em consideração os dados das pesquisas e monitoramento do público-alvo, ou a representação do cliente ideal deseja pela empresa para campanhas futuras. Nessas descrições serão detalhadas o perfil de compra, gostos, necessidades e tudo que influenciaria na compra do serviço. A seguir é apresentado a descrição de personas que podem ocasionalmente utilizar os serviços de profissionais de fotografia, de acordo com algumas características.

\section{Persona 01 Classe A:}

Laís, 24 anos, mora no Condomínio Sol Nascente, acorda às 10:00 e dorme às 02:00, cursa $4^{a}$ período em Direito na FACAPE no turno vespertino. Possui carro hatch 2017, não trabalha durante o dia, mas frequenta academia Vila Cata-vento, 5 vezes por semana. Aos finais de semana frequenta festas com área VIP pagando ingresso no débito. Consome Chandon e adora publicar o dia a dia de treinos e festas no Instagram, além de fazer live com as amigas pelo seu Smartphone Iphone 7s Plus com plano pós-pago, mas acessa a internet na maioria do tempo pelo seu notebook da Apple.

Laís (persona classe A) potencialmente consumiria o serviço de fotografia de acordo com o seu círculo de amizade e cultura. Procuraria um fotógrafo que já fotografou alguma amiga muito popular e exigente, que tenha um atendimento personalizado para fazer seu ensaio de 25 anos. Profissional que tenha bons trabalhos no Facebook, várias curtidas no Instagram e que tenha maior destaque. Decide que não basta somente ter seu ensaio em arquivos, gostou da opção de livro encadernado em papel fotográfico de capa dura com caixa personalizada com sua foto, no tamanho quadrado de $25 \mathrm{~cm}$. Ela sabe que tem alguns brindes como quadro em tamanho $60 \mathrm{~cm}$ x $90 \mathrm{~cm}$ para colocar em sua festa. A forma que o fotógrafo lhe apresentou toda a realização de um momento único, fez com que ela parcelasse $\mathrm{R} \$ 3800,00$ em duas parcelas em seu cartão de crédito. 


\section{Persona 02 Classe B:}

André, 19 anos, mora no bairro Areia Branca, acorda às 07:00 e dorme às 00:00 e cursa $1^{\circ}$ período de técnico em segurança no trabalho. Anda de bicicleta por ser saudável e fazer bem ao meio ambiente, trabalha em uma construtora como treinner, e 3 vezes por semana pratica Muay Thay na academia do bairro. Finais de semana sai para tomar cerveja em botecos com os amigos. Usa Facebook para ficar ligado nas novidades das cidades e "memes" novos, gosta de acessar pelo seu Smartphone Galaxy 7 com plano controle de $2 \mathrm{~Gb}$ por mês.

Noivo, André pesquisou entre os colegas de trabalho um fotógrafo para fazer o ensaio de prévia de casamento com a noiva. Os amigos enviaram o contato de um profissional que o no outro dia o atendeu via WhatsApp e enviou um orçamento para o celular dele. André escolheu o pacote intermediário de fotos com 20 fotos reveladas em tamanho $15 \mathrm{~cm}$ x $20 \mathrm{~cm}$. Conheceu o fotógrafo no dia do ensaio como combinado. A opção de parcelamento era em até 12x no cartão de crédito, optando ele por parcelar $\mathrm{R} \$ 890,00$ em 6 vezes no cartão de crédito.

\section{Persona 03 Classe C:}

Eduarda, 35 anos, mora no residencial do programa "Minha casa minha vida" no bairro Juazeiro 4 com seus pais aposentados, acorda às 05:30 para pegar o primeiro ônibus e chegar ao trabalho às 8:00 e sair às 18:00, como seu bairro é distante não volta para casa e segue direto para o curso de informática no centro da cidade das 18:30 às 20:00, 3 vezes por semana. Não pratica atividade física. Aos finais de semana reserva tempo para ver tv e conversar com os amigos pelo seu smartphone acessando o Facebook, usa internet de $2 \mathrm{~Gb}$ via rádio.

No final do ano, Eduarda decidiu fazer o aniversário de 60 anos da mãe e convidar alguns familiares, como sua mãe anda muito debilitada, resolveu contratar o vizinho Anderson, (estudante do ensino médio e aos finais de semana faz fotos para complementar a renda), que cobra $\mathrm{R} \$ 150,00$ para entregar as fotos em um $\mathrm{CD}$. Ela pagou $\mathrm{R} \$ 75,00$ no dia do aniversário e o que sobrou quando Anderson lhe entregasse as fotos.

A construção dessas personas, tem como objetivo mostrar a possibilidade de públicoalvo que o fotógrafo pode direcionar seu planejamento e como posicionar-se no mercado regional. 


\section{Plano de Midia}

\section{$\underline{\text { Mix de comunicação }}$}

Quadro 01 - Integração das comunicações virtuais

\begin{tabular}{|c|c|c|}
\hline $\begin{array}{l}\text { REDE } \\
\text { SOCIAL }\end{array}$ & $\begin{array}{l}\text { PRESENÇA NA REDE } \\
\text { DE COMPUTADORES }\end{array}$ & $\begin{array}{l}\text { PRESENÇA NA REDE } \\
\text { DE SMARTPHONES }\end{array}$ \\
\hline Facebook & $\begin{array}{l}\text { A criação de uma Fanpage profissional, visando } \\
\text { anexá-la ao sistema de gerenciamento de negócios do } \\
\text { Facebook, sendo capaz de gerar relatórios em } \\
\text { números vinculados ao Google Adwords. Posts com } \\
\text { fotografias de eventos e ensaios, promoções, sorteios, } \\
\text { dicas de fotografia com celular, curiosidades } \\
\text { cotidianas, etc. }\end{array}$ & $\begin{array}{l}\text { O Facebook possui seu próprio app e comunicador } \\
\text { instantâneo para a rede de smartphones, facilitando a } \\
\text { comunicação de clientes e empresas. Os usuários que } \\
\text { usam a rede pelo celular precisam disponibilidade um } \\
\text { bom plano e exercer mais paciência para isso, embora } \\
\text { seja o pioneiro nas comunicações de vendas e } \\
\text { campanhas. }\end{array}$ \\
\hline Instagram & NÃO PRESENTE NESTE CANAL & $\begin{array}{l}\text { O Instagram possibilita outra forma de interação, } \\
\text { diferente do Facebook, ele permite a participação do } \\
\text { público pela simples curtidas. Com a função de } \\
\text { empresa ativada é possível ter o acompanhamento de } \\
\text { dados demográficos de visitação, curtidas, interação, } \\
\text { parcerias com outras empresas e ver o alcance por } \\
\text { período. }\end{array}$ \\
\hline WhatsApp & NÃO PRESENTE NESTE CANAL & $\begin{array}{l}\text { A rede social mais usada hoje. Com o } \\
\text { desenvolvimento das listas de transmissão no app, o } \\
\text { incômodo dos grupos acaba e propicia um } \\
\text { atendimento personalizado e de forma mais discreta e } \\
\text { direta. É possível enviar documentos como contratos } \\
\text { de prestação de serviço e panfletos que podem } \\
\text { substituir, em partes, o papel do e-mail marketing. }\end{array}$ \\
\hline Site & $\begin{array}{l}\text { O é a casa do fotógrafo nas redes sociais, através dele } \\
\text { o cliente pode ver na íntegra como ele desenvolve seu } \\
\text { olhar dentro de seus trabalhos. É sua mídia principal, } \\
\text { sua galeria de prêmios e onde não tem a instabilidade } \\
\text { de segurança das redes sociais. }\end{array}$ & $\begin{array}{l}\text { A possibilidade dos usuários de smartphones serem } \\
\text { visitantes de sites, é através dos links presentes nas } \\
\text { redes sociais (Facebook ou Instagram) do fotógrafo. } \\
\text { Assim, é necessário que o profissional possua uma } \\
\text { plataforma totalmente responsiva para melhor } \\
\text { adaptação. }\end{array}$ \\
\hline
\end{tabular}

Estratégia de post

Persona 01 (Classe A):

Laís faz parte de 54\% das mulheres presentes no Facebook (Fonte: Social Media Update 2016), $53 \%$ dos brasileiros que seguem marcas no Instagram e $21 \%$ das pessoas entre 21 e 24 anos que acessam o Facebook (Fonte: Facebook via Hootsuite). Faz parte de 24\% das pessoas da classe alta que acessa a rede. Postagens direcionada para o público feminino (que representa $83 \%$ dos presentes na internet). $62 \%$ dos usuários da rede tem nível superior. 
A melhor hora de atingir o público da Persona 01 no Instagram, é das 02:00 às 08:00 da manhã (enquanto toma café) e 17:00 (quase final de expediente) e durante a semana, sendo a segunda-feira o melhor dia.

Gráfico 04 - Melhores dias e horários de interações no Instagram.

\begin{tabular}{|l|c|c|c|c|c|c|c|}
\hline & Domingo & Segunda & Terça & Quarta & Quinta & Sexta & Sábado \\
\hline $09: 00$ & 05 & 05 & 05 & 05 & 05 & 05 & 05 \\
\hline $10: 00$ & 05 & 05 & 05 & 05 & 05 & 05 & 05 \\
\hline $11: 00$ & 05 & 05 & 05 & 05 & 05 & 05 & 05 \\
\hline $12: 00$ & 04 & 05 & 05 & 05 & 05 & 05 & 04 \\
\hline $13: 00$ & 03 & 02 & 02 & 02 & 01 & 01 & 03 \\
\hline $14: 00$ & 05 & 04 & 04 & 04 & 03 & 03 & 05 \\
\hline $15: 00$ & 04 & 03 & 03 & 02 & 02 & 02 & 04 \\
\hline $16: 00$ & & 05 & 05 & 05 & 05 & 05 & \\
\hline $17: 00$ & & & & & & & \\
\hline $18: 00$ & & & & & & & \\
\hline $19: 00$ & & & & & & & \\
\hline $20: 00$ & & & & & & & \\
\hline
\end{tabular}

Fonte: SproutSocial via SEBRAE

$\mathbf{0 1}$ - Alto Alcance
$\mathbf{0 2}$ - Bom Alcance
$\mathbf{0 3}$ - Médio Alcance
$\mathbf{0 4}$ - Baixo Alcance
$\mathbf{0 5}$ - Péssimo Alcance

Post no Instagram: Os posts do Instagram geram uma taxa de interação por seguidor de 4,21\% -58 vezes mais interação por seguidor em comparação ao Facebook e 120 vezes mais do que o Twitter. (Fonte: Alícia Johnston, SproutSocial). Para atingir o público alvo da Persona 01 de classe alta, o fotógrafo precisa ter primeiramente objetivos traçados para eles, como aumentar o reconhecimento da marca, apresentar produtos e serviços, incentivar a interação do consumidor com o fotógrafo e conectar-se com pessoas influentes para aquele público.

Através das postagens no perfil é possível atingi-los de forma satisfatória seguindo corretamente as melhores estratégias de horários, postagens com conteúdo adequado à linguagem do público e fotografias de qualidade que transmitam aos seguidores a seriedade do trabalho.

Nas postagens é importante ter uma legenda de fácil entendimento e usando a função hashtag do Instagram para direcionar e posicionar melhor a foto nas buscas de acordo com cada segmento, usar a geolocalização também influencia no desempenho do post, além de usar a função de marcação de perfil dentro da foto a qual se aparece, no caso, em um ensaio de casal, é possível marcar as duas pessoas para que aparecem em suas linhas do tempo 


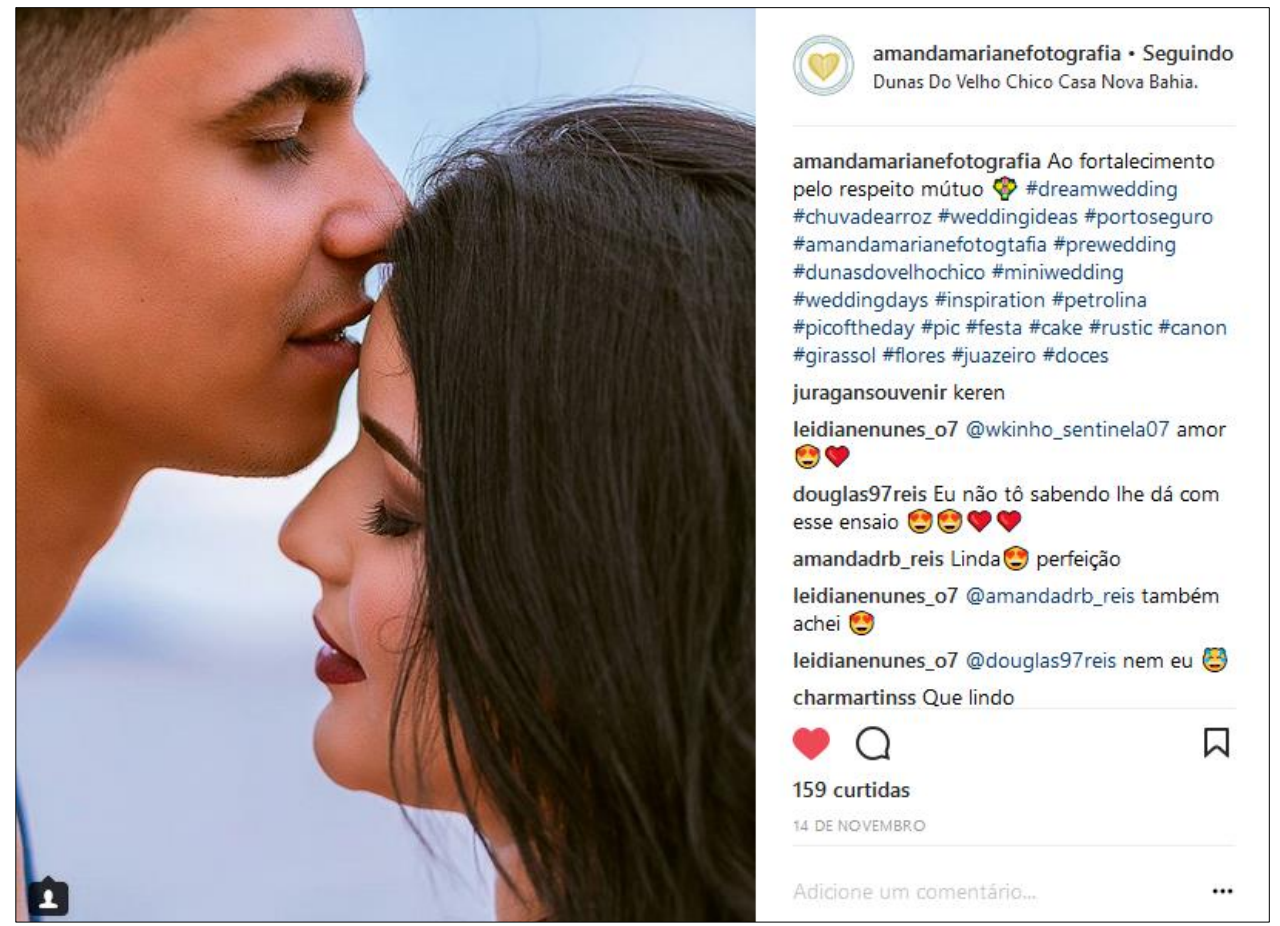

\section{Persona 02 (Classe B):}

Faz parte dos $47 \%$ dos homens que acessam o Instagram e $77 \%$ das pessoas que ainda não saíram da escola e está na classe que mais acessa o Facebook no Brasil. 58\% das postagens da internet são direcionadas para o público masculino. $15 \%$ das pessoas de que acessam o Facebook possuem entre 16 e 20 anos (Fonte: Facebook via Hootsuite).

O melhor dia para interagir com a Persona 02 no Facebook seria quinta-feira das 12:00 às 13:00, no começo da manhã (8:00 às 9:00) e final da noite (22hs as 23hs). sendo de maior interação nas 5 primeiras horas da postagem e no caso de fotografias/imagens, são responsáveis por $75 \%$ a $90 \%$ de eficácia nos anúncios de produtos ou serviços e que contenham entre 4 e 15 palavras de descrição no post.

As pessoas com as rotinas dele têm costume de acessar a rede logo cedo e antes de dormir. (Fonte: SEBRAE) 
Gráfico 05 - Melhores dias e horários de interações no Facebook.

\begin{tabular}{|c|c|c|c|c|c|c|c|}
\hline & Domingo & Segunda & Terça & Quarta & Quinta & Sexta & Sábado \\
\hline $00: 00$ & & $\mathbf{0 5}$ & $\mathbf{0 5}$ & $\mathbf{0 5}$ & $\mathbf{0 5}$ & & \\
\hline $01: 00$ & & $\mathbf{0 5}$ & $\mathbf{0 5}$ & $\mathbf{0 5}$ & $\mathbf{0 5}$ & & \\
\hline $02: 00$ & $\mathbf{0 3}$ & $\mathbf{0 2}$ & $\mathbf{0 2}$ & $\mathbf{0 2}$ & $\mathbf{0 2}$ & $\mathbf{0 2}$ & $\mathbf{0 3}$ \\
\hline $03: 00$ & & $\mathbf{0 5}$ & $\mathbf{0 5}$ & $\mathbf{0 5}$ & $\mathbf{0 5}$ & & \\
\hline $04: 00$ & & $\mathbf{0 5}$ & $\mathbf{0 5}$ & $\mathbf{0 5}$ & $\mathbf{0 5}$ & & \\
\hline $05: 00$ & & $\mathbf{0 5}$ & $\mathbf{0 5}$ & $\mathbf{0 5}$ & $\mathbf{0 5}$ & & \\
\hline $06: 00$ & & $\mathbf{0 5}$ & $\mathbf{0 5}$ & $\mathbf{0 5}$ & $\mathbf{0 5}$ & & \\
\hline $07: 00$ & & $\mathbf{0 5}$ & $\mathbf{0 5}$ & $\mathbf{0 5}$ & $\mathbf{0 5}$ & & \\
\hline $08: 00$ & $\mathbf{0 5}$ & $\mathbf{0 3}$ & $\mathbf{0 5}$ & $\mathbf{0 5}$ & $\mathbf{0 3}$ & $\mathbf{0 5}$ & $\mathbf{0 5}$ \\
\hline $09: 00$ & & $\mathbf{0 5}$ & $\mathbf{0 5}$ & $\mathbf{0 5}$ & & & \\
\hline $10: 00$ & & $\mathbf{0 5}$ & $\mathbf{0 5}$ & $\mathbf{0 5}$ & & & \\
\hline $11: 00$ & & $\mathbf{0 5}$ & $\mathbf{0 5}$ & $\mathbf{0 5}$ & & & \\
\hline $12: 00$ & & $\mathbf{0 5}$ & $\mathbf{0 5}$ & $\mathbf{0 5}$ & & & \\
\hline $13: 00$ & & $\mathbf{0 5}$ & $\mathbf{0 5}$ & $\mathbf{0 5}$ & $\mathbf{0 3}$ & & \\
\hline $14: 00$ & & $\mathbf{0 5}$ & $\mathbf{0 5}$ & $\mathbf{0 5}$ & $\mathbf{0 5}$ & & \\
\hline $15: 00$ & & & & & & & \\
\hline $16: 00$ & & $\mathbf{0 5}$ & $\mathbf{0 5}$ & $\mathbf{0 5}$ & $\mathbf{0 5}$ & $\mathbf{0 5}$ & \\
\hline $17: 00$ & $\mathbf{0 4}$ & $\mathbf{0 2}$ & $\mathbf{0 2}$ & $\mathbf{0 2}$ & $\mathbf{0 2}$ & $\mathbf{0 2}$ & $\mathbf{0 4}$ \\
\hline $18: 00$ & & $\mathbf{0 5}$ & $\mathbf{0 5}$ & $\mathbf{0 5}$ & $\mathbf{0 5}$ & & \\
\hline $19: 00$ & & $\mathbf{0 5}$ & $\mathbf{0 5}$ & $\mathbf{0 5}$ & $\mathbf{0 5}$ & $\mathbf{0 5}$ & \\
\hline $20: 00$ & & $\mathbf{0 5}$ & $\mathbf{0 5}$ & $\mathbf{0 5}$ & $\mathbf{0 5}$ & & \\
\hline $21: 00$ & & $\mathbf{0 5}$ & $\mathbf{0 5}$ & $\mathbf{0 5}$ & $\mathbf{0 5}$ & & \\
\hline $22: 00$ & & $\mathbf{0 5}$ & $\mathbf{0 5}$ & $\mathbf{0 5}$ & $\mathbf{0 5}$ & & \\
\hline $23: 00$ & & $\mathbf{0 4}$ & $\mathbf{0 4}$ & $\mathbf{0 4}$ & $\mathbf{0 4}$ & $\mathbf{0 5}$ & \\
\hline
\end{tabular}

Fonte: SproutSocial via SEBRAE
01 - Alto Alcance
02 - Bom Alcance
03 - Médio Alcance
04 - Baixo Alcance
05 - Péssimo Alcance

Post no Facebook: Apesar de os vídeos estarem ganhando muito espaço no Facebook, as imagens ainda geram duas vezes mais engajamento do que os demais conteúdos, é uma informação importante para os fotógrafos que usam a plataforma para divulgar seu trabalho. (Fonte:

www.statista.com). André faz parte dos $46 \%$ de homens e dos 28 milhões de pessoas com idade entre 18 e 24 anos que usam a rede no Brasil, são informações que são capazes de direcionar de melhor forma as publicações. Entre os usuários, $80 \%$ acessam a rede social através do Smartphone.

De acordo com a "regra do 4:1", nem só de promoções e publicidade é formado a linha do tempo das empresas no Facebook.

Segundo alguns especialistas a forma de alternar os posts publicitários e com conteúdo diversos, é a melhor maneira de atingir o público como o da Persona 02, ou seja, para cada 4 posts de conteúdos diversos, 1 seria de publicidade de negócios ou promoções. 


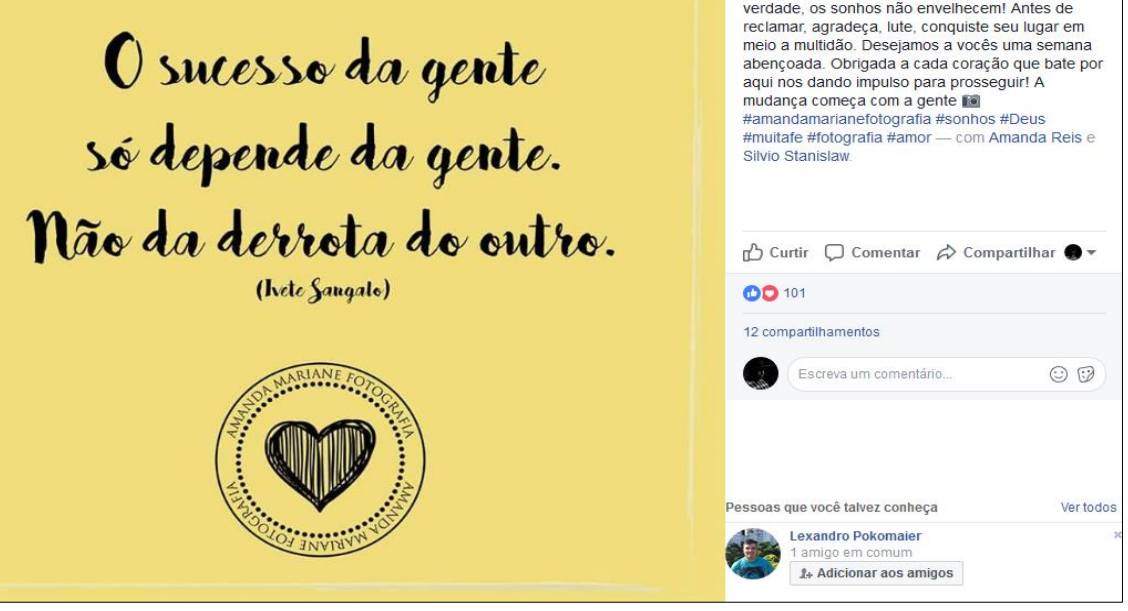

O exemplo a seguir é de um post que não representa a intenção de vendas, apresentando uma citação, que de acordo com especialistas, são responsáveis por ótimos índices de engajamento e compartilhamentos na rede social.

\section{Persona 03 (Classe C):}

Eduarda faz parte de $6 \%$ dos brasileiros que acessam a internet 1 vez por semana e faz parte dos $42 \%$ de usuários da classe C que tem 35 anos ou mais. Ela representa parte dos 54\% dos internautas da Classe C, que segundo a Google (2015), está se tornando predominante na internet em relação às outras, tendo aumentado 204\% em 10 anos.

Os internautas da classe C são responsáveis por 56\% de acessos no Facebook, o principal portal de acesso para essa classe é o smartphone, ou seja, $78 \%$ dos acessos do grupo vem dos celulares inteligentes, assim, ainda há uma apreciação da classe $\mathrm{C}$ por receber e-mails marketing. Com esses dados é indispensável ao fotógrafo que direciona postagens ou sites para o público $\mathrm{C}$, ter um site ou blog que seja responsivo - Eles são os novos donos da internet brasileira - afirma Maria Helena Marinho, diretora de Pesquisas do Google Brasil em entrevista ao O Globo (2016).

\section{Conclusões}

No decorrer de todo processo de aprendizado e conclusão da análise comportamental do mercado virtual de fotografia, foi possível observar o quão importante é o estudo voltado para 
a forma com que as redes sociais têm impacto no modo com que o público consome. Particularmente, estar inserido dentro do mercado a mais de sete anos, possibilitou ao pesquisador fortalecer seus objetivos, chancelando, através da pesquisa, a necessidade já conhecida dentre os fotógrafos que compõe seu campo de atuação na região.

Dentro do plano de montagem desse material, expõe-se da maneira mais clara possível e satisfatória concretização de todos os objetivos propostos. Dentre estes, o principal desta primeira pesquisa foi atingido, produzindo um acervo de dados referente ao comportamento dos profissionais e público nas redes sociais no Vale do São Francisco.

Analisando os dados de acordo com os objetivos específicos, constatou-se que os profissionais de fotografia devem direcionar suas publicações para as redes sociais que seu público se encontra, adequando sua linguagem quanto ao nível de instrução e bagagem cultural.

Utilizando de métodos práticos de pesquisa de campo, os dados dos gráficos, 01, 02 e 03, foram obtidos para discorrer essa pesquisa e coletados de forma que as principais características não fossem descartadas ou esquecidas. O método de questionário virtual, pela plataforma gratuita da Google, demonstrou ser viável por questões de custos e de acordo com o conhecimento do pesquisador, em relação à disponibilidade de tempo dos profissionais de fotografia, onde dedicam-se integralmente ao trabalho.

Foi observado que cada profissional abrange classes sociais diferentes além do esperado, com culturas de consumo específicas e com diferentes formas de investimento, alterando de acordo com o público que cada fotógrafo atendia, assim como ticket médio e relacionamento de seus clientes. Desta forma, a interação de cada profissional muda, sabendo que cada um tem sua peculiaridade em relação ao público-alvo. Um estudo mais aprofundado, das características dos usuários de redes sociais mostra-se necessário quando levamos em consideração que as cidades, Petrolina-PE e Juazeiro-BA, representam aproximadamente 500 mil pessoas, que apresentam características econômicas diferentes, resultando numa discrepância no modo que interagem com o mercado virtual.

Os fotógrafos apresentaram características parecidas em relação ao modo com que divulgam suas marcas, priorizando sempre os canais de comunicação de baixo custo. Ainda assim, foi constatado a presença total dos profissionais em redes sociais de grande fluxo, como o Facebook e Instagram, independentemente do público alvo. Enquanto as mídias tradicionais ( $\mathrm{TV}$, rádio, outdoor, revista e outros) não faziam parte do seu plano de marketing e não se encaixavam em seu perfil de target. 
Dentro do âmbito acadêmico do pesquisador, este trabalho significou o empenho pela melhoria do envolvimento dos profissionais de fotografia dentro das redes sociais, a fim de intensificar as vendas, dentro e fora do Vale do São Francisco. No que se refere ao crescimento pessoal, a pesquisa significou a continuação de um grande estudo para amplificar futuros trabalhos referentes ao campo do marketing na fotografia.

Por fim, os resultados atingidos com essa pesquisa, possibilitarão outros estudos a buscarem através de novas ferramentas, compreender o processo de comunicação entre fotógrafo e público através dos canais de comunicação virtual. Assim, uma vez analisado o perfil do mercado de fotografia profissional no Vale do São Francisco, torna-se importante a continuidade de pesquisas tanto nessa área quanto em outras áreas, visando a melhoria das condições de comunicação com os clientes.

Como sugestões para pesquisas futuras, orientamos aos profissionais de fotografia - e outras áreas também, que façam uso das ferramentas de pesquisa de marketing digital para identificar oportunidades, medirem desempenho empresarial e profissional, receber feedback e definir melhor sua estratégia de planejamento nas redes. Saber preferências e detalhes da demanda, faz a diferença na definição das estratégias corporativas. A análise dos ambientes e do comportamento e necessidade do público pode auxiliar na escolha de segmento, tecnologia, práticas gerenciais, dentre outros.

\section{Referências}

CERVO, Amado Luiz. Et al. Metodologia científica. 6ed. São Paulo: Pearson Prentice Hall, 2007.

COBRA, Marcos. Marketing Básico: uma perspectiva brasileira. São Paulo: Atlas, 2007.

COBRA, MARCOS - (1991) Administração estratégica do mercado. São Paulo: Atlas 1991.

E. Jerome McCarthy. Basic Marketing, A Managerial Approach, Richard D. Irwin, Inc., Homewood, Ill., 1960, seção F.

HAIR, J. F.; BABIN, B.; MONEY, A.H.; SAMUEL, P. Fundamentos métodos de pesquisa em administração. Porto Alegre: Bookman, 2005. (verificar se pode colocar no rodapé)

KOTLER, P.; ARMSTRONG, G. Princípios de Marketing. Rio de Janeiro: Prentice Hall do Brasil, 1993.

KOTLER, Philip; KELLER, Kelvin Lane. Administração de Marketing. 12.ed. São Paulo: Pearson Prentice Hall, 2006. 
LAKATOS, E. M.; MARCONI, M. de A. Metodologia científica. 2. ed. São Paulo, Atlas S. A., 1991.

LAS CASAS, Alexandre Luzzi. Conceitos, Exercícios, Casos. 7ed. São Paulo: Atlas, 2005.

LAUTERBORN, Robert F. O novo paradigma do marketing: como obter resultados mensuráveis através do uso do database e das comunicações integradas do marketing. São Paulo: MakronBooks, 1994.

MARCONI. M. A.; LAKATOS, E. M. Técnicas de pesquisa. São Paulo: Atlas, 1999.

RECUERO, Raquel. A nova revolução: as redes são as mensagens. In: BRAMBILLA, Ana (Org.). Para entender as mídias sociais. 2011. Disponível em: http://paraentenderasmidiassociais.blogspot.com, acesso em 30/11/2016.

RICHERS, Raimar. 1926 - O que é marketing I Raimar Richers. - 15. ed. — São Paulo: Brasiliense, 1994. - (Coleção primeiros passos; 27)

SILVA, Polyana Inácio Rezende. Dinâmicas comunicacionais na vida cotidiana - Instagram: um modo de narrar sobre si, fotografar ou de olhar pra se ver. In: XVII CONGRESSO DE CIÊNCIAS DA COMUNICAÇÃO NA REGIÃO SUDESTE, 2012, Ouro Preto. Artigo Científico. Ouro Preto: Intercom - Sociedade Brasileira de Estudos Interdisciplinares da Comunicação, 2012.

SOLOMON, Michael. O Comportamento do Consumidor: comprando, possuindo e sendo. $5^{\text {a }}$. Edição. Porto Alegre: Bookman, 2002.

VAZ, Conrado Adolpho. Google marketing: o guia definitivo de marketing digital. 3. ed. São Paulo: Novatec, 2010.

\section{Como citar este artigo (Formato ABNT):}

OLIVEIRA, Silvio Stanislaw A. de; CAFFÉ FILHO, Hesler P. Redes Rociais e Mercado Fotográfico do vale do São Francisco. Id on Line Rev.Mult. Psic., 2018, vol.12, n.40, p.78-100. ISSN: 19811179.

Recebido: $15 / 02 / 2018$

Aceito 17/02/2018 